REVIEWS OF INFECTIOUS DISEASES - VOL. 4, NO. 4 - JULY-AUGUST 1982 1982 by The University of Chicago. All rights reserved. 0162-0886/82/0404-0024502.00

\title{
Sociocultural Factors in the Control and Prevention of Parasitic Diseases
}

\author{
Leonardo Mata
}

\author{
From the Instituto de Investigaciones en Salud, \\ Universidad de Costa Rica, \\ Ciudad Universitaria Rodrigo Facio, Costa Rica
}

\begin{abstract}
Control and prevention of parasitic disease depends on an adequate knowledge of interactions among factors such as human behavior, the environment, and the life cycles of parasites. Sociocultural factors in large part determine transmission and persistence of parasites. The main determinants are poverty, low educational level, deficiencies in home technologies, high demographic density, and ruralism. Selected interventions designed to improve any of these situations may fail if they are applied in an isolated manner. The holistic implementation of interventions has proved successful in the control and prevention of parasitic infections in several parts of the world. The implementation of several kinds of interventions simultaneously, that is, a holistic approach, combined with an awareness of a society's infrastructure, can produce favorable results. For such an awareness - when it provokes action-can improve the overall quality of life.
\end{abstract}

The complexity of controlling and preventing parasitic disease stems from the fact that humans and parasites have evolved through millions of years in constant interaction with each other and with the environment. The result is an enormous variety of life cycles and ecological situations, ranging from the simple to the highly complex or even bizarre. Control is then difficult because one must take into consideration not only the nature and natural history of the parasites, but also the biological characteristics and behavior of the humans involved and the environmental circumstances under which they dwell.

As was classically illustrated by Stoll [1], humans live in a wormy world (especially in the tropics and subtropics), whether in relatively undeveloped or in industrialized countries. The list of worms that are pathogenic for humans is still long (table 1) and will get longer as unexpected parasites cross species barriers. Furthermore, new parasitic entities are always being discovered; the relatively recent additions include Capillaria

This work was supported by the Vice-Presidency of Research Affairs, University of Costa Rica; the International Union of Nutritional Sciences; the U. S. Agency for International Development; the British Overseas Development Agency; and the Rockefeller Foundation.

1 wish to thank Drs. Ramiro Barrantes, Rodrigo Brenes, Mario Vargas, and Alfonso Trejos for aid and criticism.

Please address requests for reprints to $\mathrm{Dr}$. Leonardo Mata, Instituto de Investigaciones en Salud, Universidad de Costa Rica, Ciudad Universitaria Rodrigo Facio, Costa Rica. philippinensis [2], which causes an enteropathy characterized by protein loss and malabsorption, and Angiostrongylus costaricensis [3], which causes eosinophilic granulomas in children.

Regardless of the diversity in natural history of humans and parasites, infection is generally acquired by $(l)$ ingestion of food, water, or soil that has been contaminated with feces or urine carrying eggs or cysts of parasites; (2) acquisition of cysts or eggs from another person (person-toperson transmission); or (3) exposure to vectors carrying infective stages or to larvae of the parasites (e.g., cercariae) released into the environment. This situation explains the multiplicity of infection often seen in poor, underdeveloped regions of the world. For instance, data on rates of infection with intestinal parasites among children of a typical Mayan Indian village of Guatemala (table 2 ) indicate a very high prevalence and the coexistence of multiple infections [4]. Because the village is in the highlands (elevation, $\sim 6,000$ feet), and migration to coastal areas is negligible, neither hookworm nor vector-borne parasitic infections are prevalent. This pattern contrasts with the situation of poor villages in lowland tropical regions, where transmission of arthropod-borne infections is intense, as illustrated by data from Chad (table 3) [5]. The latter situation is more critical because, in addition to the vector-borne infections, villagers in Chad and in similar ecosystems also bear the burden of many intestinal parasites. 
Table 1. Worms important in human infections.

\begin{tabular}{|c|c|}
\hline $\begin{array}{l}\text { Ascaris lumbricoides } \\
\text { Toxocara canis } \\
\text { Lagochilascaris minor } \\
\text { Anisakis species } \\
\text { Phocanema species } \\
\text { Contracaecum species } \\
\text { Enterobius vermicularis } \\
\text { Strongyloides stercoralis } \\
\text { Micronema deletrix } \\
\text { Trichostrongylus orientalis, } \\
\text { T. axei, T. colubriformis, } \\
\text { T. vitrinus } \\
\text { Oesophagostomum species } \\
\text { Ancylostoma duodenale, } \\
\text { A. coninum, A. braziliensis } \\
\text { Necator americanus } \\
\text { Angiostrongylus cantonensis, } \\
\text { A. costaricensis } \\
\text { Wuchereria bancrofti, } \\
\text { W. malayi } \\
\text { Brugia malayi } \\
\text { Loa loa } \\
\text { Onchocerca volvulus } \\
\text { Dipetalonema perstans, } \\
\text { D. streptocerca } \\
\text { Mansonella ozzardi } \\
\text { Dirofilaria inmitis, D. tenuis } \\
\text { Dracunculus medinensis } \\
\text { Gnathostoma spinigerum } \\
\text { Trichuris trichiura } \\
\text { Capillaria philippinensis, } \\
\text { C. hepatica }\end{array}$ & $\begin{array}{l}\text { Trichinella spiralis } \\
\text { Heterophyes heterophyes } \\
\text { Metagonimus yokogawai } \\
\text { Gastrodiscoides hominis } \\
\text { Fasciolopsis buski } \\
\text { Echinostoma revolutum } \\
\text { Fasciola hepatica, F. gigantica } \\
\text { Clonorchis sinensis } \\
\text { Opistorchis felineus, } \\
\text { O. viverrini } \\
\text { Dicrocoelum dendriticum } \\
\text { Paragonimus westermani, } \\
\text { P. africanus, P. skrjabini, } \\
\text { P. heterotremus, P. mexi- } \\
\text { canus, P. uterobilateralis } \\
\text { Schistosoma mansoni, S. } \\
\text { japonicum, S. haematob- } \\
\text { ium, S. intercalatum, S. } \\
\text { mattheei, S. bovis, S. spin- } \\
\text { dale, S. rodhaini } \\
\text { Taenia saginata, T. solium } \\
\text { Echinococcus granulosus, E. } \\
\text { multilocularis, E. oligar- } \\
\text { thrus, E. vogelsi } \\
\text { Multiceps multiceps, M. seri- } \\
\text { alis, M. brauni } \\
\text { Hymenolepsis nana, H. } \\
\text { diminuta } \\
\text { Dipylidium caninum } \\
\text { Diphyllobothrium latum } \\
\text { Spirometra mantsanoides }\end{array}$ \\
\hline
\end{tabular}

\section{Priorities for Control and Prevention}

Each parasite has its particular habitat and, in general, a complex life cycle intimately intertwined with and determined by the biological characteristics and behavior of humans. Even as a desk exercise, the designing of intervention programs for control and prevention of parasitic infections is possible only when much is known about host and parasite. It appears convenient to select those parasites that are most damaging to humans in terms of morbidity, nutrition, mortality, and economic losses. At a global level, the list of important parasites includes about 20 species for which priority can be established (table 4). The problem should be examined in each nation by means of well-established criteria. The parasites listed are important, but skepticism about their overall public-health significance may arise (e.g., Chagas' disease in certain regions of the American continent). Also, the significance of
Table 2. Prevalence of intestinal parasites among threeyear-old children in a village of Guatemala.

\begin{tabular}{lcc}
$\begin{array}{l}\text { No. of species } \\
\text { per person* }\end{array}$ & $\begin{array}{c}\text { Rate of } \\
\text { infection (\%) }\end{array}$ & $\begin{array}{c}\text { Cumulative } \\
\text { prevalence (\%) }\end{array}$ \\
\hline 0 & 2.4 & \\
1 & 30.9 & 97.6 \\
2 & 23.8 & 66.5 \\
3 & 19.0 & 42.7 \\
4 & 9.5 & 23.7 \\
5 & 7.1 & 14.2 \\
26 & 7.1 & 7.1 \\
\hline
\end{tabular}

NOTE. Data are from [4].

* Values given include all intestinal parasites, four of the most common being Ascaris lumbricoides $(77.8 \%)$, Giardia lamblia (19.1\%), Entamoeba histolytica $(10.4 \%)$, and Trichuris trichiura $(3.0 \%)$.

such highly prevalent parasites as Ascaris lumbricoides and Entamoeba histolytica must be judged as a function of geographic location, epidemiologic determinants, and nutritional status. For instance, E. histolytica is prevalent and causes serious disease in Mexico [6], but not in Central America. On the other hand, Ascaris seems important wherever malnutrition exists since it contributes to wastage $\{7\}$.

Walsh and Warren [8] established priorities for the control of various global parasitic infections (table 5). Limitations on control are due in great part to sociocultural restraints in the populations involved. Effective control measures apparently exist only for malaria and hookworm, but even with these infections there are problems in certain ecosystems resulting from a particular type of human behavior. Furthermore, human intervention with insecticides and antiparasitic drugs has induced the emergence of and resistance to chemical agents among vectors and parasites.

The priorities in table 5 cannot be generalized to all nations alike. There are well-known areas where control of schistosomiasis and Chagas' disease is a high priority. In other regions, hookworm and cutaneous leishmaniasis are progressively disappearing because of socioeconomc and cultural changes. Furthermore, some parasitic diseases have been controlled to a significant extent in advanced societies (industrial nations) - and, more recently, in countries in transition-as a result of an improvement in the quality of life. For instance, in Costa Rica, the incidence of cutaneous leishmaniasis appears to be decreasing [9], 
Table 3. Prevalence of systemic parasites in a village of Chad.

\begin{tabular}{lcc}
$\begin{array}{lcc}\text { No. of species } \\
\text { per person* }\end{array}$ & $\begin{array}{c}\text { Rate of } \\
\text { infection }(\%)\end{array}$ & $\begin{array}{c}\text { Cumulative } \\
\text { prevalence }(\%)\end{array}$ \\
\cline { 2 - 3 } 0 & 2.6 & 97.4 \\
1 & 17.6 & 79.8 \\
2 & 47.1 & 32.7 \\
3 & 21.0 & 11.7 \\
4 & 10.1 & 1.6 \\
5 & 0.8 & 0.8 \\
6 & 0.8 & 0 \\
7 & 0 & 0
\end{tabular}

NOTE. Data are adapted from [5].

- Values given include all intestinal parasites, with individual rates and sites of infection as follows: Onchocerca volvulus (skin), 91.6\%; Plasmodium falciparum and Plasmodium malariae (blood), 43.7\%; Schistosoma mansoni (stool), 36.1\%; Dipetalonema perstans (blood), 28.6\%; Loa loa (blood), 9.2\%; Schistosoma hoematobium (urine), 7.6\%; and Wuchereria bancrofti (blood), $5.0 \%$.

that of intestinal parasitism and diarrhea has been significantly reduced [10, 11], malaria is largely under control, and Bancroft's filariasis remains circumscribed to its original niche in Puerto Limón on the Atlantic coast [12, 13].

Once priorities are established, the life cycles and transmission mechanisms of the prevalent parasites should be examined to see how human sociocultural characteristics favor infection. Table 6 lists the means of transmission of the main parasitic infections. Transmission to humans may be from an invertebrate (mosquito, reduviid,
Table 4. Parasites of high prevalence in humans at a global level.

Plasmodium falciparum, $P$. vivax

Trypanosoma gambiense, $T$. rhodesiense

Trypanosoma cruzi

Leishmania donovani, L. tropica, L. brasiliensis, L. mexicana

Entamoeba histolytica

Giardia lamblia

Schistosoma japonicum, S. haematobium, S. mansoni

Dracunculus medinensis

Onchocerca volvulus

Wuchereria bancrof $t i$

Ascaris lumbricoides

Trichuris trichiura

Ancylostoma duodenale, Necator americanus

Strongyloides stercoralis

snail) or a vertebrate animal host or from another human. The parasite undergoes important changes in the vector that lead to development of the infective form. This model demands complex logistics for control: the habitat and behavior of each vector must be known and taken into account as a function of the complex way of life of humans in the various ecosystems. Furthermore, in the control of parasites that have other vertebrate hosts (and may, in fact, represent zoonoses), the complex relationships of these hosts with humans and the environment must be considered.

The other type of transmission is simpler because it involves the passage of the parasite from person to person. Although it may require maturation of infective forms in the outside environ-

Table 5. Priorities for intervention to control parasitic diseases in developing countries, 1980.

\begin{tabular}{|c|c|c|c|c|}
\hline \multirow[b]{2}{*}{ Priority, disease } & \multicolumn{4}{|c|}{ Criterion } \\
\hline & Prevalence & Morbidity & Mortality & Control \\
\hline \multicolumn{5}{|l|}{ High } \\
\hline Malaria & High & High & High & Effective \\
\hline Hookworm & High & High & Low & Effective \\
\hline \multicolumn{5}{|l|}{ Medium } \\
\hline Schistosomiasis & High & Low & Low & Difficult \\
\hline Onchocerciasis & Medium & High & Low & Difficult \\
\hline \multicolumn{5}{|l|}{ Low } \\
\hline African trypanosomiasis & Low & High & High & Difficult \\
\hline Filariasis & High & Low & Low & Difficult \\
\hline Visceral leishmaniasis & Low & Low & Low & Difficult \\
\hline Giardiasis & High & Low & Very low & Difficult \\
\hline Ascariasis & High & Low & Very low & Difficult \\
\hline Amebiașis & High & Very low & Very low & Difficult \\
\hline Chagas' disease & Low & Very low & Very low & Difficult \\
\hline Cutaneous leishmaniasis & Low & Very low & Very low & Difficult \\
\hline
\end{tabular}

NOTE. Data are adapted from [8]. 
Table 6. Transmission of major parasites to humans.

\begin{tabular}{|c|c|c|c|}
\hline $\begin{array}{l}\text { Route of transmission, } \\
\text { vector (if any) }\end{array}$ & Mechanism & Infective form & Parasite \\
\hline \multicolumn{2}{|c|}{ Vertebrate-invertebrate-vertebrate (humans) } & & \\
\hline Mosquito & Inoculation & Sporozoites & Plasmodium \\
\hline Mosquito & Inoculation & Promastigotes & Leishmania* \\
\hline Black fly & Penetration & Third-stage larvae & Onchocerca \\
\hline Mosquito & Penetration & Third-stage larvae & Wuchereria \\
\hline Tse tse fly & Inoculation & Metacyclic trypomastigotes & Trypanosoma (African) \\
\hline Reduviid & Penetration & Metacyclic trypomastigotes & Tryponosoma (American)* \\
\hline Crustacean & Ingestion & Larvae & Dracunculus* \\
\hline Snail & Penetration & Cercariae & Schistosoma* \\
\hline \multirow[t]{3}{*}{ Human-human } & Penetration & Third-stage larvae & Hookworm \\
\hline & Ingestion & Embryonated eggs & Ascaris, Trichuris \\
\hline & Ingestion & Cysts & Giardia, Entamoeba \\
\hline Vertebrate-human & $\begin{array}{l}\text { Ingestion } \\
\text { Ingestion }\end{array}$ & $\begin{array}{l}\text { Cysticerci } \\
\text { Embryonated eggs }\end{array}$ & $\begin{array}{l}\text { Taenia saginata, } T \text {. solium } \\
T . \text { solium }\end{array}$ \\
\hline
\end{tabular}

NOTE. There are other forms of transmission, for instance, man-invertebrate-vertebrate-man, such as in Diphyllobothrium latum.

- There could be more than one vertebrate hosi.

ment, direct person-to-person transmission appears to be important, for instance, with some intestinal protozoa. While parasites with invertebrate hosts may be more difficult to control, the behavior of . humans in underdeveloped tropical and subtropical regions favors persistence and interferes with control and prevention of disease caused by parasites that are transmitted from person to person.

\section{Sociocultural Factors and Acquisition of Infection}

The fact that incidence of several parasitic infections is decreasing in certain areas that have improved their social and economic situations is a good indication of the relevance of human living standards as a determinant of infection. This relation is well illustrated for malaria, hookworm, and other declining parasitic diseases in Costa Rica, Cuba, and Trinidad-Tobago; a dramatic example involves the control of schistosomiasis in China [14]. Table 7 describes factors favoring establishment of infection with parasites of global significance. Determinants such as poverty, lack of education, and crowding are central to the issue. Religious practices are another variable.

For hookworm infection, ascariasis, amebiasis, and other intestinal parasitic diseases, the determining behavioral factor is defecation on the ground near streams and water reservoirs, which favors contamination of the environment. Indiscriminate squatting results in pollution of home premises, foods, drinking water, and agricultural fields. Infection is usually acquired by ingestion of water and food directly or indirectly contaminated with feces. Transmission from person to person as a result of poor personal hygiene, crowding, and sleeping of several persons in one bed is also important in certain parasitic infections. Behavioral research is needed in order to understand and modify patterns of life that maintain transmission [15].

For schistosomiasis, defecation and urination on the ground near streams and water reservoirs favor contamination of the snail's habitat. Infected snails eventually discharge cercariae into the water, and these larvae infect humans. Ablution favors spread, particularly in the low socioeconomic classes, who must defecate near water sources because of sociocultural traits and prevailing conditions. Squatting at dawn and night also favors exposure to mosquito-borne and hookworm infection.

With guinea worm infection, a serious disabling disease, the larvae emerge from human tissues through broken skin blisters and fall into the water, where they establish themselves inside small crustaceans. Infection is spread to humans who drink water harboring infected Cyclops [16]. Evidently, control demands community knowl- 
Table 7. Sociocultural determinants of parasitic infection.

\begin{tabular}{|c|c|}
\hline Infection & Factors* \\
\hline Hookworm & Squatting, ablution; agricultural practices; lack of shoes \\
\hline $\begin{array}{l}\text { Giardiasis, amebiasis, } \\
\text { ascariasis, trichuriasis }\end{array}$ & $\begin{array}{l}\text { Squatting, ablution; ingestion of contaminated food, water, and soil; } \\
\text { living in crowded quarters }\end{array}$ \\
\hline Schistosomiasis & Squatting, ablution; agricultural practices; bathing in contaminated water \\
\hline Guinea worm & Contact with or drinking of contaminated water \\
\hline Malaria, filariasis & Poor housing; outdoor activities after dark \\
\hline Chagas' disease & Poor housing; animal reservoirs in or around homes \\
\hline Sleeping sickness & Working in endemic savanna \\
\hline Onchocerciasis, leishmaniasis & Dwelling and working near ecologic niches \\
\hline
\end{tabular}

- The main determinants of parasitic infection that are reflected by these relatively specific factors are poverty, low educationa] level, deficient home technology, high population density, ruralism, and dispersion.

edge of how disease is acquired; in the absence of this information, preventive measures cannot be taken.

Significant control of malaria has been attained in the past with little regard for sociocultural factors; rather, reliance has been placed mainly on the use of insecticides, treatment, and chemoprophylaxis. However, the development of insecticide resistance in vectors, of drug resistance in Plasmodium, and of an increase in extradomiciliary habits of humans has made control more difficult and has set back eradication of malaria in many areas of the world. These complicating factors demand both aggressive research into new approaches to control and greater understanding of the disease among the affected populations [17].

With regard to Chagas' disease, poor housing and crowding are crucial factors because they favor contact between reservoir hosts (domestic animals), humans, and the reduviids harboring Trypanosoma cruzi [18]. Similarly, maintenance of Bancroft's filiariasis depends on the availability of individuals with microfilaremia to domiciliary arthropod vectors. Poor housing, unprotected sleeping, and outdoor activities after dark are important elements in transmission.

The relation of humans to cattle in the pasture lands and to water sources determines exposure to tsetse flies. Rates of infection with African trypanosomes vary as a function of distance to these endemic foci [19].

Onchocerciasis is transmitted by black flies dwelling in well-defined ecological niches. Acquisition depends on exposure to bites of Simulium in endemic areas and is favored by agricultural practices and ruralism [5].

In cutaneous leishmaniasis, infection is main- tained in mammals inhabiting the forest [20]. Humans acquire the disease when they clear the forest land or hunt or when they settle in endemic areas [21]. Special behaviors, such as hunting at night, account for the acquisition of infection only by adult males in certain circumstances [22]. In other instances, dwelling near the habitat of the animal reservoirs (e.g., the hyrax of Ethiopia) is the determining factor for infection of humans [23].

Recent observations by our group revealed that the epidemiology of cutaneous leishmaniasis among Amerinds of Costa Rica, varied according to the degree of clearing of and contact with the virgin forest. The appearance of lesions was more intense and precocious in one locality of the Guaymi (Limoncito), where people live in close contact with relatively virgin forest, than in another (Abrojos), where part of the forest had been cleared. When skin tests (reaction) were performed, $33 \%$ of children five to nine years old in Abrojos and $86 \%$ in Limoncito reacted to Leishmania (author's unpublished observations).

\section{Main Determinants of Parasitic Infection}

The main determinants of transmission of parasitic infection are prevailing poverty, deficient education, deficient home technology, high demographic density, and ruralism. These determinants account for the choice of habitats, ways of life, and other important elements that are required for maintenance of infection in humans.

Poverty and low educational level. Poverty and a low educational level coexist with and strongly determine poor housing, deficient personal hygiene, and equivocal attitudes toward 
health and disease. Poverty characterizes families with low income or no income at all, deficient maternal (familial) technology, dependence on subsistence agriculture, and lack of sociopolitical development.

Poverty, crowding, and inadequate technology interfere with procurement of the needed amounts of food and exacerbate parasitic infection. The situation may be complicated by seasonality; negative conditions are accentuated during certain seasons of the year in many parts of the world, with an increased risk of infection and malnutrition $[24,25]$. Such considerations alone make it difficult to design and effect successful methods for control and prevention. In the correction of these deficiencies, the holistic (integral) approach is certainly the most promising [4].

Maternal (familial) technology. Our observations in a highland Mayan Indian village revealed that certain child-rearing practices and attitudes of mothers (and other members of the family) may be more important in the transmission of disease and the development of malnutrition than socioeconomic class or degree of schooling. Behavior of mothers is often related to training during their own childhood and adolescence. The wealth of maternal information has been called maternal technology [26]. Elements in this technology include ( $I$ ) the handling and storage of water; $(2)$ the preparation, handling, and storage of food; (3) the care of children during illness; (4) alimentation during convalescence; (5) attitudes toward primary health care; (6) disposal of excreta and waste; (7) personal hygiene; (8) patterns of eating and sleeping; $(9)$ proclivity to improve housing and environmental sanitation; and (10) pattern of socializing. A particular mother may store drinking water in a separate earthen jar with a narrow mouth; this simple measure may prevent contamination of the water with pathogenic organisms. Such behavior is not necessarily based upon a concept of causality of disease. Most mothers in the village we studied store water in a large jar, and such all-purpose water becomes contaminated. If a mother habitually boils water, her family may be protected from such contamination.

Inadequate hygiene results in food contamination in the home [27]. In contrast, adequately prepared (well-cooked and well-ground) mixes, purees, and mashes of locally available foods are excellent for children during weaning and for all family members during convalescence from illness. Some mothers limit the intake of food by children during illness and convalescence, while others maintain breast-feeding at these times, thus diminishing deterioration of the child's nutritional status. A deficiency in maternal technology increases the risk of exposure to viruses, bacteria, and parasites and also enhances the negative effects of infection while decreasing the host's capacity to cope with infection.

An important element of maternal technology is a positive attitude toward primary health-care services, which often conflicts with traditional medicine and the local customs and beliefs. Some mothers readily accept the value of primary health care, particularly vaccination, deworming, oral rehydration, and family planning; others fail to do so. Wray and Aguirre [28] advanced the concept of "maternal incompetence:" the failure - unintentional or intentional-to seek medical attention for a child who is suffering from a condition such as acute diarrheal disease, dehydration, or serious infection. Other elements of maternal technology concern habits of eating, sleeping, defecation, ablution, and socializing, all of which are highly relevant to disease transmission [29]. Maternal incompetence and inadequte maternal technology, along with other behavioral factors and social stresses, favor disease transmission and decrease the quality of life.

High population density and ruralism. These two main determinants of infection may have a positive or negative effect, depending on the degree of socioeconomic development. For instance, a high population density in less developed societies favors the spread of parasitic infection, since traditional behavior leads to environmental contamination and to the perpetuation of vectorborne parasites and of carriers and reservoirs of disease. A few individuals harboring parasites easily seed the environment and expose a large number of people to infection in crowded, underdeveloped conditions. This situation accounts in part for the extremely high prevalence of parasitic infections throughout the less developed tropical countries (tables 2 and 3 ). However, if the level of education rises and personal and environmental hygiene improves, infections can remain circumscribed to a few families within a given community, even if crowding prevails.

Ruralism and population dispersion mean that 
isolated families in forest, jungle, or desert have poor access (or no access) to health services, educational facilities, and markets [24]. In socioculturally undeveloped conditions, traditions, beliefs, and taboos persist, as do contamination of the environment and exposure to ecologic niches of parasites. Infections, malnutrition, and other health problems are prevalent and exert their maximal effect under such conditions. However, if significant sociocultural development is attained-as seems to be the case in TrinidadTobago, Taiwan, Puerto Rico, and Costa Ricaruralism and dispersion of the rural population may become an asset. First, communication between families may take considerable time, and this delay curtails the spread of disease. Second, if the family enjoys a high level of maternal (familial) technology, entrenchment of certain parasites, such as hookworm, becomes difficult. In fact, intestinal parasitism in rural Costa Rica now appears to exist only in families with the lowest level of sociocultural development (author's unpublished observations). Furthermore, our observations on the Amerindian Guaymi, who live in marked isolation and dispersion, reveal a lower incidence of intestinal infection than in crowded urban neighborhoods that are more advanced economically. In addition, nutritional wasting and severe forms of malnutrition have not been detected among Guaymi children $[30,31]$.

\section{The Holistic Approach}

A historical appraisal of the results of intervention programs designed to reduce the incidence of infection and malnutrition shows that programs involving food supplementation, installation of latrines, supervision of water supplies, and prenatal care have had very limited impact or have failed to improve the conditions they were supposed to modify [32]. More often than not, the overall cost of the programs precludes implementation among populations who live in areas that are difficult to reach. Cost-benefit analysis indicates that primary health care is probably the most feasible type of intervention for rural developing regions [8].

On the other hand, history teaches a relevant lesson: the incidence of leading infectious diseases declined significantly in Europe and North America before the causes and specific preventive measures were discovered [33]. Furthermore, there is evidence that the orthodox approach to diagnosis and treatment of disease often does not work when underdevelopment prevails and when intervention programs are implemented cross-culturally $[4,34]$. Observation clearly indicates that control of seriously debilitating diseases is attained through an improvement of sanitation, housing, and education - that is, the quality of life $[35,36]$. Thus, social determinants of disease are the most important factors to identify when planning intervention programs.

The holistic approach (implementation of several types of intervention simultaneously) appears to be the most reasonable means of improving the quality of life. Unfortunately, the cost and effort of such an approach may be staggering in many developing nations. Thus, the holistic approach demands political decisions. These decisions may be catalyzed by the sustained efforts of an outspoken scientific community. However, pressure from the affected population and the eventual politicization of health may be the most important forces in the mobilization of public health programs. The scientific community must of fer various alternative solutions to the problems that are identified.

The holistic approach requires an infrastructure for primary health care. The emphasis should be on maternal and child health, with these interrelated goals: $(l)$ promotion of optimal nutrition through breast-feeding for several months and adequate food supplementation during the first two to three years of life; (2) control of diarrheal disease by oral rehydration and proper alimentation during illness and convalescence; (3) prevention of diarrheal disease and parasitic infection by improvement of personal and home hygiene; (4) immunization against the common communicable diseases of childhood; (5) community organization for improvement of the environment (water supply, latrines, waste disposal) and surveillance of health; (6) chemotherapy and chemoprophylaxis where malaria and other drug-susceptible parasitic diseases are prevalent; and (7) family planning.

Research on the environmental, sociocultural, and behavioral factors relevant to parasitic infection is needed. A research model different from the purely biomedical one is in order [37]; emphasis should be placed on health services and the transfer of technologies to the organized commun- 
ity. The collaboration of researchers in biomedicine, social sciences, and planning presumably will yield better results than have been obtained so far. A next step is the definition of priorities for intervention in each nation and in the various ecosystems within each country. Finally, research should focus on ethnic, cultural, and behavioral factors that determine infection, malnutrition, and underdevelopment in the community. The assessment of priorities for research must be an ongoing exercise, while attempts at control and prevention through the application of existing knowledge should continue. Also, efforts should take into account cost-benefit analyses for improvement of health-care delivery services.

An understanding of the complexity of the determinants of parasitic infection should stimulate governments to undertake the application of the holistic approach. The importance of considering several interrelated measures instead of isolated steps has been pointed out in many investigations and is clear from day-to-day experience. The decision to tackle the holistic approach should be backed by political commitment, a situation that is incompatible with government policy (or lack of policy) in many less-developed countries. No efforts to implement the holistic approach should be neglected by politicans and scientists since the alternatives will lead only to more disease, malnutrition, and suffering, as was predicted and observed in Central America [4].

\section{References}

1. Stoll, N. R. This wormy world. J. Parasitol. 33:1-18, 1947.

2. Chitwood, M. B., Velesquez, C., Salazar, N. G. Capillaria philippinensis sp. N. (Nematoda: Trichinellida), from the intestine of man in the Philippines. J. Parasitol. 54:368-371, 1968.

3. Morera, $P_{.+}$Cespedes, R. Angiastrongylus costaricensis n. sp. (Nematoda: Metastrongyloidea), a new lung worm occuring in man in Costa Rica. Rev. Biol. Trop. 18:173-185, 1971.

4. Mata, L. J. The children of Santa María Cauqué: a prospective field study of health and growth. The MIT Press, Cambridge, Mass., 1978. 395 p.

5. Buck, A. A. Global problem of onchocerciasis and its economic impact. Scientific publication no. 298. Pan American Health Organization. Washington. D.C., 1947, p. 3-9.

6. Sepúlveda, B. La amebiasis invasora por Entamoeba histolytica. Gac. Med. Mex, 100:201-254, 1970.

7. Stephenson, L. S., Crompton, D. W. T., Latham, M. C.,
Schulpen, T. W. J. Nesheim, M. C., Jansen, A. A. J. Relationships between Ascaris infection and growth of malnourished preschool children in Kenya. Am. J. Clin. Nutr. 33:1165-1172, 1980.

8. Walsh, J. A., Warren, K. S. Selective primary health care. An interim strategy for disease control in developing countries. N. Engl. J. Med. 301:967-974, 1979.

9. Hidalgo, H., Jaramillo, O. Contribución a la epidemiología de la leishmaniasis en Costa Rica. Acta Médica Costarricense 20:83-101, 1977.

10. Morales, M. T., Lizano, C. Cambios observados en la problemática del parasitismo intestinal en las últimas dos décadas. Revista Médica Hospital de Niños 13:7178, 1978.

11. Mata, L., Mohs, E. As seen from national levels: developing world. In S. Margen and R. A. Ogar led.]. Progress in human nutrition. Vol. 2. Ari Publishing Co., Westport, Conn., 1978, p. 254-264.

12. Butts, D. C. A. Filarial infection in Costa Rica. Am. J. Trop. Med. 27:607-615, 1947.

13. Brenes, R., Duarte, G. A., Solano, M. E. Revisión sobre filariasis de Bancroft en Costa Rica. Acta Médica Costarricense 22:431-434, 1979.

14. Hsu, H. F., Li Hsu, S. Y. Schistosomiasis in the Shanghai area. In J. R. Quinn [ed.]. China medicine as we saw it. U.S. Department of Health, Education and Welfare, 1974 , p. 345-363.

15. Dunn, F. L. Behavioural aspects of the control of parasitic diseases. Bull. WHO. 57:499-512, 1979.

16. Neafie, R. C., Connor, D. H., Meyers, W. M. Dracunculiasis. In C. H. Binford and D. H. Connor [ed.]. Pathology of tropical and extraordinary diseases. Armed Forces Institute of Pathology, Washington, D.C., 1976, p. $397-401$.

17. Barnes, S. Malaria eradication in Surinam: prospects of success after five years of health education. Int. J. Health Educ. 11:20-31, 1968.

18. Zeledón, R. Epidemiology, modes of transmission and reservoir hosts of Chagas' disease. Ciba Found. Symp. 20:51-77, 1974.

19. Baker, J. R. Epidemiology of African sleeping sickiness. Ciba Found. Symp. 20:30-43, 1974.

20. Herrer, A., Christensen, H. A., Beumer, R. J. Reservoir hosts of cutaneous leishmaniasis among Panamanian forest mammals. Am. J. Trop. Med. Hyg. 22:585-591, 1973.

21. Herrer, A., Christensen, H. A. Epidemiological patterns of cutaneous leishmaniasis in Panama. I. Epidemics among small groups of settlers. Ann. Trop. Med. Parasitol. 70:59-65, 1976.

22. Herrer, A., Christensen, H. A., Beumer, R. J. Epidemiological patterns of cutaneous leishmaniasis in Panama. 11. Incidental occurrence of cases in non-endemic settlements. Ann. Trop. Med. Parasitol. 70:67-71, 1976.

23. Bray, R. S. Epidemiology of leishmaniasis: some reflections on causation. Ciba Found. Symp. 20:87-100, 1974.

24. Chambers, R. Health, agriculture, and rural poverty: why seasons matter. Institute for Developmental Studies, University of Sussex, England, 1979. 26 p.

25. Chambers, R., Longhurst, R., Bradley, D., Feachem, R. 
Seasonal dimensions to rural poverty: analysis and practical implications. Institute for Developmental Studies, University of Sussex, England, 1979.28 p.

26. Mata, L. J. The malnutrition-infection complex and its environment factors. Proc. Nutr. Soc. 38:29-40, 1979.

27. Barrell, R. A. E., Rowland, M. G. M. Infant foods as a potential source of diarrhoeal illness in rural West Africa. Trans. R. Soc. Trop. Med. Hyg. 73:85-90, 1979.

28. Wray, J. D., Aguirre, A. Protein-calorie malnutrition in Candelaria, Colombia. I. Prevalence, social and demographic causal factors. J. Trop. Pediatr. 15:76-98, 1969.

29. Aziz, K. M. S. Existing environmental conditions in rural areas of Bangladesh and its relation to important community diseases. Cholera Research Laboratory, Dacca, Bangladesh, 1978. $15 \mathrm{p}$.

30. Mata, L. J. Los derechos del niño. Marco para intervenciones prioritarias en salud. Arch. Latinoam. Nutr. 30: $314-334,1980$.
31. Mata, L. Child deprivation and malnutrition: observations in Guatemala and Costa Rica. Food Nutr. (Roma) 6: $7-14,1980$.

32. Keusch, G. T., Katz, M. [ed.]. Effective interventions to reduce infection in malnourished populations. Am. J. Clin. Nutr. 31:2035-2356, 1978.

33. Kass, E. H. Infectious disease and social change. J. Infect. Dis. 123:110-114, 1971.

34. MeDermott, W., Deuschle, K. W., Barnett, C. R. Health care experiment at Many Farms. Science 175:23-31, 1972.

35. Dubos, R. Mirage of health. Doubleday, New York, 1959.

36. McDermott, $W$. Modern medicine and the demographic disease pattern of overly-traditional societies: a technological misfit. J. Med. Educ. 41(Suppl.):137-162, 1966.

37. Engel, G. L. The need for a new medical model: a chatlenge for biomedicine. Science 196:129-136, 1977. 